\title{
Effects of metallic ions and diphosphonates on inhibition of pericardial bioprosthetic tissue calcification and associated alkaline phosphatase activity
}

\author{
Danielle Hirsch, Frederick J. Schoen* and Robert J. Levy \\ Department of Pediatrics, University of Michigan Medical School, Ann Arbor, Mi 48109-0576; and \\ *Department of Pathology, Brigham and Women's Hospital and Harvard Medical School, Boston, MA, USA
}

This study focused on the association of extrinsic alkaline phosphatase (AP) activity with both early and advanced calcification of glutaraldehyde-pretreated bovine pericardial bioprosthetic (GPBP) tissue, and the inhibition of both calcification and AP activity by pre-incubation in diphosphonates (sodium-ethanehydroxydiphosphonate [NaEHDP],

aminopropanehydroxydiphosphonate [APD]) and metallic salts $\left(\mathrm{FeCl}_{3}, \mathrm{Ga}\left(\mathrm{NO}_{3}\right)_{3}, \mathrm{AlCl}_{3}\right) . \mathrm{GPBP}$ specimens were implanted subcutaneously in $3 \mathrm{wk}$ old male rats after pre-incubation. Following explantation of the tissue at $72 \mathrm{~h}$ and $21 \mathrm{~d}$, calcification was assessed morphologically by light microscopy and chemically by atomic adsorption spectroscopy for calcium content and by molybdate complexation for phosphorus. AP activity was characterized by enzymatic hydrolysis of paranitrophenyl phosphate and by histochemical studies. In both control and pretreated groups, AP levels were greater in $72 \mathrm{~h}$ explants than $21 \mathrm{~d}$ retrievals, which demonstrated extensive calcification in control explants. All pre-incubations that resulted in inhibition of calcification after $21 \mathrm{~d}$, except for APD, were associated with $72 \mathrm{~h}$ AP content which was lower than control specimens. The typical time of initiation of calcification was $72 \mathrm{~h}$, as determined by previous studies with this model system. Covalently bound APD inhibited calcification. Increased AP activity in the APD group may be due to the toxicity of this agent with resultant acute inflammation, or other incompletely understood effects of diphosphonates on calcification and AP. Furthermore, EHDP and $\mathrm{Ga}^{3+}$ incubations were also associated with decreased GPBP AP at $72 \mathrm{~h}$ compared to control, but were not effective for inhibiting calcification after $21 \mathrm{~d}$. We concluded that inhibition of peak GPBP AP activity is not necessarily associated with the prevention of GPBP mineralization.

Keywords: Bovine pericardium, calcification, alkaline phosphatase

Received 5 August 1992; accepted 21 October 1992

Bioprosthetic heart valves fabricated from either glutaraldehyde-pretreated porcine aortic valve cusps or bovine pericardium (GPBP) are often used to replace deteriorating human cardiac valves. The primary reason for the clinical failure of porcine aortic valve bioprostheses is dystrophic calcification ${ }^{1-3}$. Calcification also contributes to the failure of bovine pericardial valves. Bioprosthetic heart valve calcification occurs as a multifactorial process, in which an interaction of host factors (youth), implant factors (glutaraldehyde fixation) and implant factors (stress-strain) are crucial $^{1-6}$. Calcification of clinical bioprosthetic valves can be simulated either by

Correspondence to Dr D. Hirsch. large animal circulatory models or by subdermal implants in rodents ${ }^{4-6}$. The initial calcification event in the rat subdermal model is the mineral deposition in devitalized cells intrinsic to the bioprosthetic tissue within 48-72 h, followed later by collagen mineralization.

Matrix vesicles (MV) present in the extracellular matrix of mineralizing tissues are considered to initiate deposition of hydroxyapatite mineral in endochondral bone formation and calcific diseases ${ }^{7}$. An enrichment of alkaline phosphatase (AP) within the MVs suggests an important role for this enzyme in the initiation of calcification $^{8,9}$; following nucleation, AP activity declines during progressive bone mineralization ${ }^{10}$. However, some studies have shown that AP catalytic activity is not 
absolutely required for MV calcification ${ }^{10}$. The fact that the enzyme was found distributed widely in tissues that normally do not undergo mineralization has raised questions as to the specificity of the relationship between AP and calcification ${ }^{11}$.

Research has demonstrated AP activity in glutaraldehyde-pretreated porcine aortic valve tissue ${ }^{12}$ and $\mathrm{GPBP}^{13}$ before and after glutaraldehyde fixation. However, after fixation AP activity is only detectable by histochemistry, and is not extractable using the established butanol extraction procedure ${ }^{13}$. Furthermore, subdermal implant studies have demonstrated peak extractable AP levels in GPBP after $72 \mathrm{~h}$ implantation, coinciding with the onset of calcification ${ }^{13}$. AP activity declined thereafter, while bulk mineral increased ${ }^{13}$. In previous studies, metallic salt pre-incubations, which included either ferric chloride or aluminium chloride, have been shown to inhibit calcification of GPBP tissues in the rat subdermal model ${ }^{14,15}$. This inhibition was associated with reduced AP activity after $21 \mathrm{~d}^{13}$. These metallic inhibitors have also been shown to be localized to the site at which AP is present ${ }^{15}$. This is probably due to the high affinity of these cations for membrane-associated phosphorus-rich sites, which have also been shown to be the loci of the initial calcific deposits. Furthermore, diphosphonates are potent calcification inhibitors ${ }^{16-18}$. Their mechanism of action appears to be the marked affinity of these compounds for crystalline calcium phosphates ${ }^{19.20}$. In addition, diphosphonates also influence cellular metabolism; dichloromethanediphosphonate and sodium ethanehydroxydiphosphonate increased the AP activity of cultured rat calvaria cells ${ }^{21}$, and in vivo, chickens treated with these diphosphonates demonstrated inhibition of bone mineralization associated with increased AP activity ${ }^{22}$.

The present study was carried out to understand the effects of diphosphonates and metallic salts on both calcification and AP activity during dystrophic mineralization of rat subdermal implants of GPBP. The goals of this study were to: (1) document the effects of various inhibitors of GPBP calcification on early ( $72 \mathrm{~h}$ ) and late (21 d) mineralization and AP accumulation in rat subdermal implants; (2) to examine further the morphologic distribution of AP with either progression or inhibition of GPBP mineralization; and (3) to assess the effects of possible calcification inhibitors on the $\mathrm{Ca}-\mathrm{P}$ mineral phase, as indicated by $\mathrm{Ca} / \mathrm{P}$ ratios.

\section{MATERIALS AND METHODS}

\section{Materials}

Electron microscopy-grade glutaraldehyde was purchased as an $8 \%$ aqueous solution (Polyscience, Warrington, PA, USA). The buffer used for cross-linking and incubation of the drugs included $50 \mathrm{mM} \mathrm{N}$-2-hydroxyethylpiperazine$N^{\prime}$-2-ethanesulphonic acid (HEPES, Sigma Chemical, St Louis, MO, USA) with $0.1 \mathrm{M} \mathrm{NaCl}$ (EM Science, Cherry Hill, NJ, USA). Ferric chloride hexahydrate (reagent grade) and the phosphate standard were obtained from Sigma Chemical, St Louis, MO, USA. Gallium nitrate (99\%) and ammonium molybdate (VI) were obtained from Aldrich (Milwaukee, WI, USA]. Aluminium chloride was obtained from Mallinckrodt (Paris, KY, USA). Aminopropanehydroxydiphosphonate (APD) was donated by $\mathrm{Dr}$ James Benedict (Intermedics Orthopedics Inc., Wheatridge, CO, USA]. Sodium ethanehydroxydiphosphonate (NaEHDP) was donated by Procter and Gamble (Cincinnati, OH, USA). L-ascorbic acid was purchased from Fisher Chemical (FairLawn, NJ, USA). 2-amino-2methyl-1-propanol, sec-butanol, $p$-nitrophenyl phosphate (pnpp) and $p$-nitrophenol (pnp) were also obtained from Sigma.

\section{Methods}

\section{In vitro incubations}

Fresh mature bovine parietal pericardium was obtained from the slaughter house (P. Dunbar, Milan, MI, USA) and immediately cross-linked for $24 \mathrm{~h}$ in $0.6 \%$ glutaraldehyde at $\mathrm{pH} 7.4$ (50 $\mathrm{mM}$ HEPES buffer) at $4^{\circ} \mathrm{C}$, then stored for $2-4 \mathrm{wk}$ in $0.2 \%$ glutaraldehyde in the same buffer at $4^{\circ} \mathrm{C}$, as described previously ${ }^{5,6,23}$. GPBP was cut into $1 \mathrm{~cm}$ diameter pieces and rinsed free of glutaraldehyde.

Following fixation and storage, the GPBP pieces were pre-incubated for $24 \mathrm{~h}$ at room temperature in either APD, or NaEHDP both at concentrations of $0.1 \mathrm{M}$, buffered to $\mathrm{pH} 7.4$ plus $\mathrm{NaCl}(0.1 \mathrm{M})$. GPBP pieces were also pre-incubated in several metallic salt solutions at $\mathrm{pH} 3(0.001 \mathrm{M} \mathrm{HCl}, \mathrm{NaCl} 0.1 \mathrm{M})$ including $\mathrm{AlCl}_{3}(0.1 \mathrm{M})$, $\mathrm{Ga}\left(\mathrm{NO}_{3}\right)_{3}(0.1 \mathrm{M}), \mathrm{FeCl}_{3}$ (both $0.1 \mathrm{M}$ and $10^{-4} \mathrm{M}$ ). Control specimens of GPBP were pre-incubated in either $\mathrm{pH} 7.4$ [50 mM HEPES] or $\mathrm{pH} 3(0.001 \mathrm{M} \mathrm{HCl})$ solutions $[0.1 \mathrm{M}$ $\mathrm{NaCl}$ ) for $24 \mathrm{~h}$ at room temperature.

\section{Implant and retrieval methods}

After pre-incubation in the various solutions, the GPBP specimens were washed with sterile saline, and then implanted subdermally in male, weanling rats $[50-60 \mathrm{~g}$, CD, Sprague-Dawley, Charles River Laboratories, Burlington, MA, USA) according to methods described previously ${ }^{5,6,15,18,23}$. The rats were anaesthetized by an i.m. injection of ketamine hydrochloride and xylazine. Ten GPBP specimens were implanted subdermally per rat (six in the abdominal wall and four in the dorsal wall) (five rats per group study). At $72 \mathrm{~h}$, five pieces (from the abdominal implant site) were removed under anaesthesia. After $21 \mathrm{~d}$, the rats were killed by $\mathrm{CO}_{2}$ asphyxiation and the remaining samples retrieved.

\section{Biochemical analysis}

Explants were rinsed with copious volumes of saline and deionized water, freeze-dried, minced and subjected to acid hydrolysis as described previously ${ }^{5,23}$. Aliquots of the hydrolysates were analysed for calcium by atomic absorption and for phosphorus using a molybdate complexation ${ }^{24}$. AP enzymatic activity was quantitated as described previously ${ }^{12}$. Briefly, butanol extracts of 5$6 \mathrm{mg}$ GPBP samples were assayed for hydrolysis of pnpp normalized by Lowry protein content ${ }^{25}$ (pH 10.4 and $37^{\circ} \mathrm{C}$ at a wave length of $405 \mathrm{~nm}$ using a Lambda $3 \mathrm{~B}$ spectrophotometer (Perkin-Elmer, Oak Brook, IL, USA).

\section{Morphologic analysis}

A representative sample of each GPBP explant was placed in Karnovsky's fixative ${ }^{26}$ for subsequent morpho- 
Table 1 Inhibition of glutaraldehyde pretreated bovine pericardium (GPBP) calcification and alkaline phosphatase (AP) activity: rat subdermal implant results

\begin{tabular}{|c|c|c|c|c|c|c|c|c|c|c|c|}
\hline \multirow[t]{2}{*}{ Pretreatment } & \multicolumn{6}{|c|}{$72 \mathrm{~h}$ Explants } & \multicolumn{5}{|c|}{$21 \mathrm{~d}$ Explants } \\
\hline & $\mathrm{Ca}^{*}$ & $P^{*}$ & & $\mathrm{AP}^{\star \star *}$ & & $\mathrm{Ca} / \mathrm{P}^{* \star \star}$ & $\mathrm{Ca}^{*}$ & $P^{*}$ & & $A P^{\star *}$ & $\mathrm{Ca} / \mathrm{P}^{* * *}$ \\
\hline $\begin{array}{l}\text { Control (pH 7.4) } \\
\text { APD (0.1 M) } \\
\text { NaEHDP }(0.1 \mathrm{M}) \\
\text { Control }(\mathrm{pH} 3) \\
\mathrm{FeCl}_{3}(0.1 \mathrm{M}) \\
\mathrm{FeCl}_{3}\left(10^{-4} \mathrm{M}\right) \\
\mathrm{Ga}\left(\mathrm{NO}_{3}\right)_{3}(0.1 \mathrm{M}) \\
\mathrm{AlCl}_{3}(0.1 \mathrm{M})\end{array}$ & $\begin{array}{l}2.2+0.20(4) \\
2.1 \pm 0.60(5) \\
1.5 \pm 0.06(5) \\
3.2 \pm 1.40(2) \\
4.8 \pm 0.30(5) \\
2.3 \pm 0.50(5) \\
5.2 \pm 0.80(5) \\
9.8 \pm 0.60(5)\end{array}$ & $\begin{array}{l}0.7 \\
1.4 \\
0.4 \\
0.6 \\
2.9 \\
1.04 \\
2.3 \\
7.4\end{array}$ & $\begin{array}{l} \pm 0.10(4) \\
\pm 0.60(5) \\
\pm 0.04(5) \\
\pm 0.30(2) \\
\pm 0.10(5) \\
\pm 0.20(5) \\
\pm 0.30(5) \\
\pm 0.40(5)\end{array}$ & $\begin{array}{l}317.30 \pm \\
576.60 \pm \\
165.60 \pm \\
249.60 \pm \\
185.90 \pm \\
490.10 \pm \\
217.00 \pm \\
93.07 \pm\end{array}$ & $\begin{array}{c}41.4(7) \\
85.0(12) \dagger \\
14.3(13) \dagger \\
49.2(9) \\
34.1(13) \\
145.3(14) \\
34.6(12) \\
8.5(12) \dagger\end{array}$ & $\begin{array}{l}2.7 \\
1.1 \\
3.3 \\
4.3 \\
1.2 \\
1.7 \\
1.7 \\
1.7\end{array}$ & $\begin{array}{c}90.0 \pm 5.9(4) \\
3.4 \pm 0.6(5) \dagger \\
89.3 \pm 8.7(5) \\
95.6 \pm 25.9(3) \\
19.0 \pm 3.0(5) \dagger \\
93.3 \pm 14.2(5) \\
98.0 \pm 5.34(5) \\
9.3 \pm 0.5(5) \dagger\end{array}$ & $\begin{array}{r}45.20 \pm \\
1.50 \pm \\
84.20 \pm \\
52.00 \pm \\
12.30 \pm \\
50.60 \pm \\
102.30 \pm \\
25.26 \pm\end{array}$ & $\begin{array}{r}2.3(4) \\
0.2(5) \\
24.2(5) \\
13.6(3) \\
2.2(5) \\
8.1(5) \\
29.2(5) \\
4.3(5)\end{array}$ & $\begin{aligned} & 78.2 \pm 15.2(4) \\
& 101.7 \pm 20.0(9) \\
& 52.4 \pm 6.9(10) \\
& 42.9 \pm 5.8(6) \\
& 157.6 \pm 76.6(10) \\
& 87.4 \pm 7.7(10) \dagger \\
& 103.6 \pm 40.0(10) \\
& 33.7 \pm 2.6(10)\end{aligned}$ & $\begin{array}{l}1.5 \\
1.7 \\
0.8 \\
1.4 \\
1.2 \\
1.4 \\
0.7 \\
0.3\end{array}$ \\
\hline
\end{tabular}

Mean $\pm S E M$.

${ }^{*} \mu \mathrm{g} / \mathrm{mg}$ of dried tissue.

** $\mathrm{nm}$ paranitrophenyl phosphate/min/mg protein

*** Molar ratio.

$\dagger P<0.05$ compared with controls.

() Number in parentheses is the number of analyses

logical analysis. For histochemical demonstration of AP, a separate GPBP explant sample from each drug group were frozen with dry ice in several drops of OCT medium (Miles Inc., Elkhart, IN, USA] for subsequent cryomicrotomy and AP staining assessment, using the conventional method ${ }^{27}$. Sections of GPBP $(10 \mu \mathrm{m}$ thick) were cut with a cryomicrotome, mounted on glass slides, and dried at room temperature. The sections were incubated at $37^{\circ} \mathrm{C}$ for $30 \mathrm{~min}$ in a medium for $\mathrm{AP}$ modified from Gomori ${ }^{27}$ containing $50 \mathrm{ml}$ of $5 \mathrm{mM} \mathrm{MgCl}_{2}$ in distilled water, $1 \mathrm{mI}$ Naphtol AS-MX phosphate in pH 10.5 buffer (Sigma), and $25 \mathrm{mg}$ Fast Red TR or Fast Blue RR (Sigma) as described previously ${ }^{12}$.

\section{RESULTS}

The calcium and phosphorus levels, together with the AP activity data at $72 \mathrm{~h}$ and $21 \mathrm{~d}$, are summarized in Table 1. No extractable AP activity from unimplanted GPBP was noted by enzymatic analyses. Explant GPBP AP enzymatic activity was higher in all groups after $72 \mathrm{~h}$ than in $21 \mathrm{~d}$ explants, despite lower calcium levels in all the $72 \mathrm{~h}$ explants compared with $21 \mathrm{~d}$ results. The mean calcium and phosphorus levels in the pretreated GPBP $72 \mathrm{~h}$ explants did not statistically differ significantly for all the drug pre-incubation groups and control groups (Table 1). Except for the APD group, all pre-incubations which resulted in inhibition of calcification after $21 \mathrm{~d}$, compared to the control, also demonstrated lower AP levels than control in the $72 \mathrm{~h}$ explant specimens (Figure 1). Morphological assessment qualitatively confirmed these results (Figures 2 and 3 ). Although covalently bound APD significantly inhibited calcification in $21 \mathrm{~d}$ explants compared to controls (which were heavily calcified), maximal AP levels for all groups at $21 \mathrm{~d}$ were noted in the APD group (Figures 2 and 3). In contrast, pretreatment with NaEHDP did not inhibit GPBP calcification compared to control after $21 \mathrm{~d}$, although the AP activity was sightly lower than the control in $72 \mathrm{~h}$ and $21 \mathrm{~d}$ explants.

$\mathrm{Ga}\left(\mathrm{NO}_{3}\right)_{3}(0.1 \mathrm{M})$ and $\mathrm{FeCl}_{3}\left(10^{-4} \mathrm{M}\right)$ pre-incubations failed to inhibit calcification. However, $\mathrm{FeCl}_{3}(0.1 \mathrm{M})$ and $\mathrm{AlCl}_{3}(0.1 \mathrm{M})$ pre-incubations inhibited calcification, and the latter was associated with the lowest AP levels and

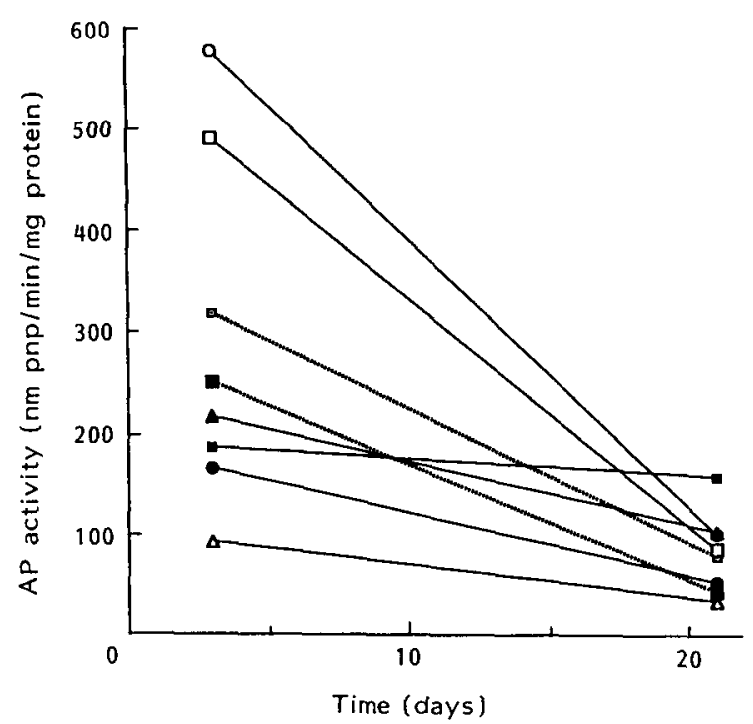

a

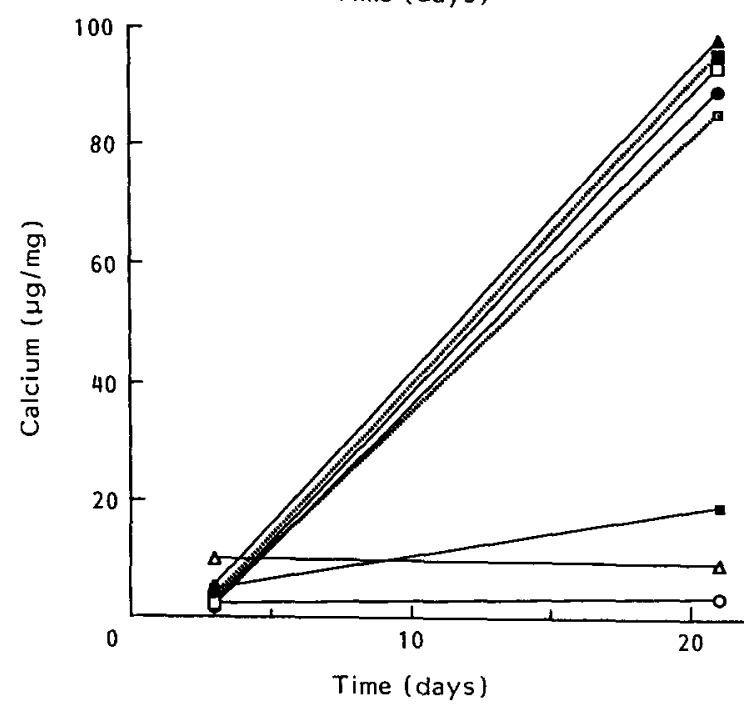

Figure 1 a, Alkaline phosphatase (AP) activity levels normalized per extractable protein content and b, calcium levels/mg dry weight of GPBP control tissues and drug-treated tissues at initiation stage of calcification $(72 \mathrm{~h})$ and at $21 \mathrm{~d}$ interval calcification. 'II' 1111 , control (Ctrl) (pH 7.4); aminohydroxypropanediphosphonate (APD) $(0.1 \mathrm{M})$; -

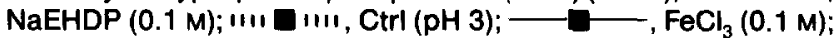
$-\square-\mathrm{FeCl}_{3}\left(10^{-4} \mathrm{M}\right) ;-\mathbf{-}-\mathrm{Ga}\left(\mathrm{NO}_{3}\right)_{3}(0.1 \mathrm{M})$; $\longrightarrow \triangle-\mathrm{AlCl}_{3}(0.1 \mathrm{M})$. 

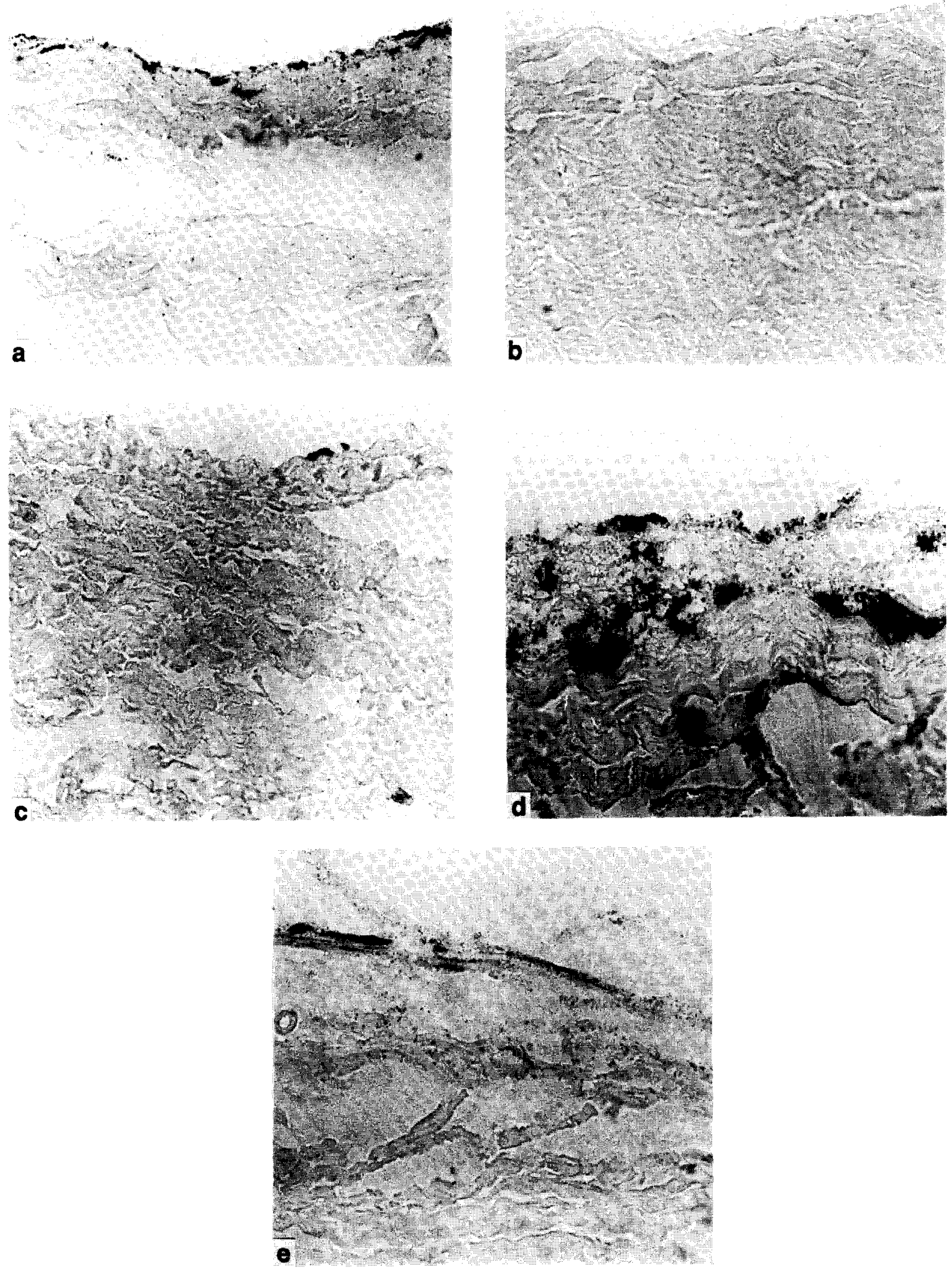

Figure 2 Effects of pretreatment in $\mathrm{AICl}_{3}$ and aminodiphosphonate (APD) on histochemical staining of alkaline phosphatase (AP) accumulation in bovine pericardium implanted subcutaneously in rats. a, and $\mathbf{b}$, Control (untreated) bovine pericardium at 3 and $21 \mathrm{~d}$, respectively. c, $\mathrm{AlCl}_{3}$ pre-incubated bovine pericardium following $3 \mathrm{~d}$ implantation. $\mathrm{d}$ and e, APD pretreated tissue at 3 and $21 \mathrm{~d}$ respectively. AP (dark reaction product) is evident in the control bioprosthetic tissue, $\mathbf{a}, \mathbf{b}$, at $3 \mathrm{~d}$ and is comparatively reduced at $21 \mathrm{~d}$. AP activity is scarcely evident in $72 \mathrm{~h} \mathrm{AlCl}_{3}$ explants, c. However, AP activity is enhanced compared to controls at both 3 and $21 \mathrm{~d}, \mathrm{~d}$, e, in the APD-pretreated tissue. Original magnification $\times 230$. 


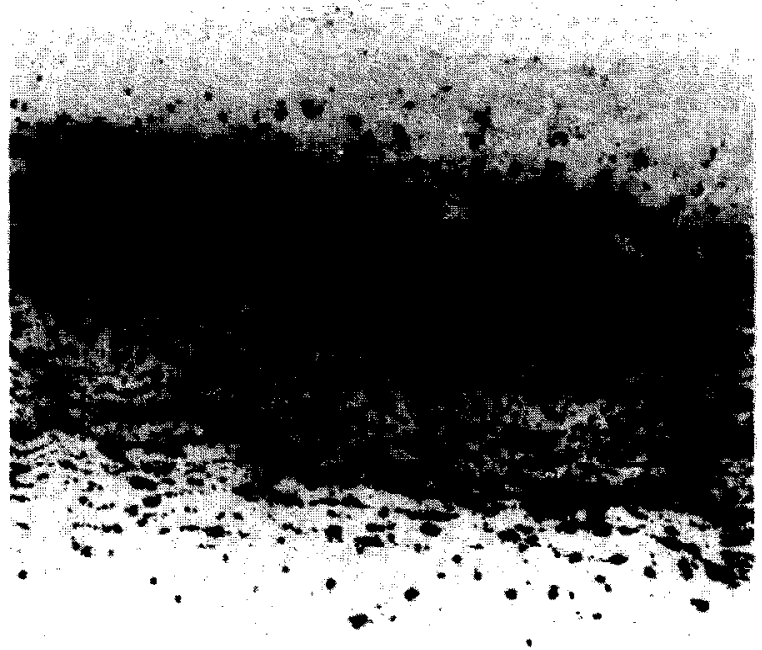

a

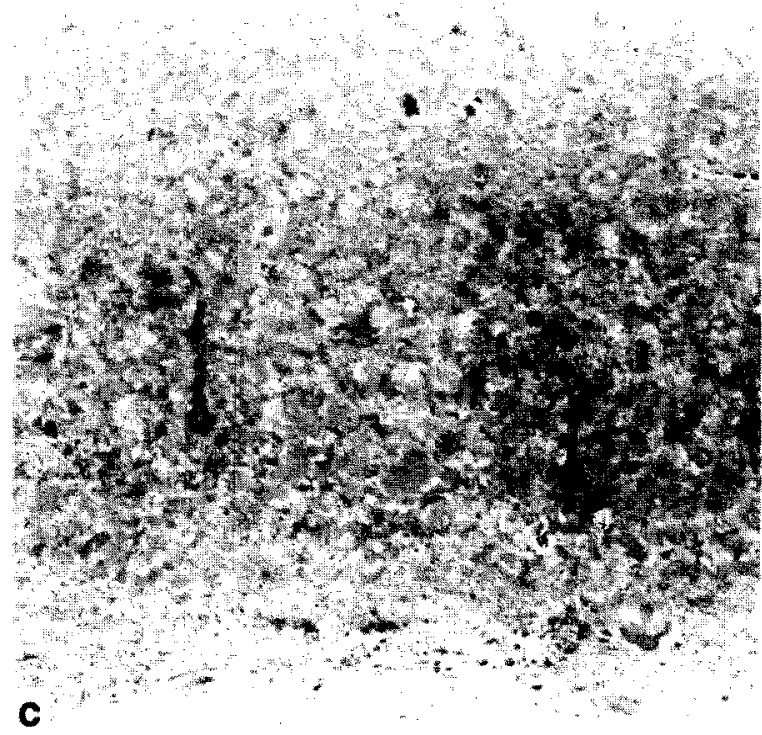

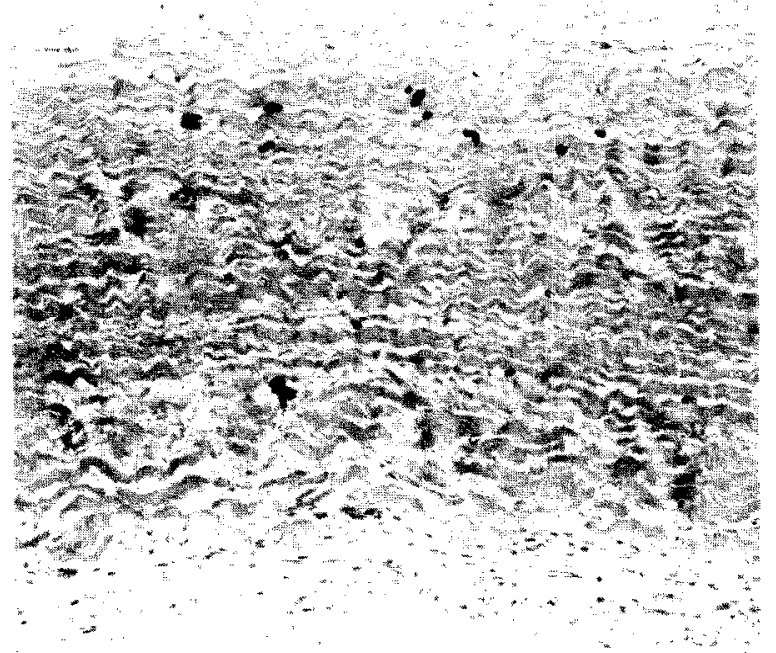

b

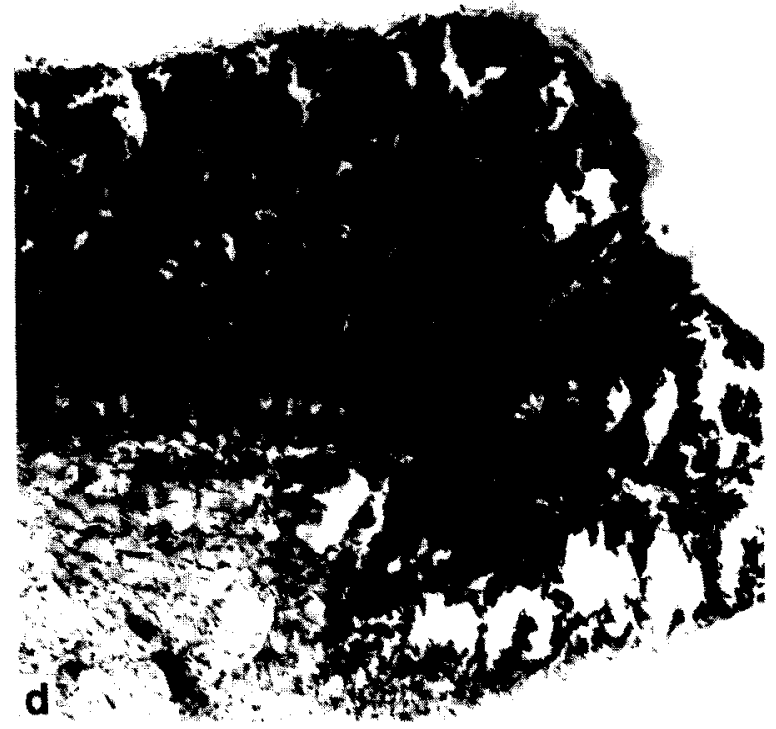

Figure 3 Light microscopy appearance of calcification of bovine pericardium implanted subcutaneously in 3 wk old rats for $21 \mathrm{~d}$. a, Control tissue demonstrating heavy mineralization. b. Tissue pretreated in APD demonstrating sparse punctate calcific deposits (probably in cells). c, Tissue pretreated in $\mathrm{FeCl}_{3}(0.1 \mathrm{M})$, demonstrating complete absence of mineralization. $\mathrm{d}$, Tissue pretreated in gallium, demonstrating heavy mineralization. Each stained with von Kossa stain (calcium phosphate black). Original magnification $\times 120$.

decline in AP ( $21 \mathrm{~d}$ versus $72 \mathrm{~h}$ ) of the various groups. AP activities in the $\mathrm{Ga}^{3+}$ group were slightly lower than controls after $72 \mathrm{~h}$, and even slightly greater than controls after $21 \mathrm{~d}$. Nevertheless, $\mathrm{Ga}^{3+}$ failed to inhibit calcification. $\mathrm{Ga}^{3+}$ explants demonstrated the highest $\mathrm{P}$ levels of all groups after $21 \mathrm{~d}$. These may nucleate further Ca-P deposition.

$\mathrm{Ca} / \mathrm{P}$ molar ratios of the $21 \mathrm{~d}$ explant groups demonstrated were consistent with the presence of calcium phosphate for the control groups and the $\mathrm{FeCl}_{3}\left(10^{-4} \mathrm{M}\right)$ specimens. However, the calcified $\mathrm{Ga}\left(\mathrm{NO}_{3}\right)_{3}$ and $\mathrm{NaEHDP}$ groups each demonstrated a relatively higher phosphorus content and hence lower $\mathrm{Ca} / \mathrm{P}$ ratios than usually noted with hydroxyapatite deposition.

\section{DISCUSSION}

Interestingly, peak GPBP AP activities were noted on the $72 \mathrm{~h}$ explants regardless of pre-incubation in solutions of diphosphonates or metallic ions. Earlier results showed that AP activity peaks in the first $72 \mathrm{~h}$ in control GPBP rat subdermal explants; by this time calcification is also initiated $^{12}$. However, comparisons between the various groups (control and pre-incubation) did not reveal a trend consistently linking reduced GPBP with inhibition of calcification. Thus, although AP activity and inhibition of AP may be associated with the onset and progression of GPBP calcification, the present results support the view that AP may be one of several determinants of the pathogenesis of GPBP calcification. Therefore, AP inhibition or enhancement by various inhibitors may not reveal the importance of $\mathrm{AP}$ in this setting.

Furthermore, previous work from our group has shown that extrinsic GPBP AP activity declines following its peak at $72 \mathrm{~h}$ as mineralization progresses. Comparable observations were reported in studies of the onset of bone mineralization involving endochondral MV calcification ${ }^{10}$. In the case of MVs, this decline in AP activity is not due 
to proteolysis, but rather to the calcification process itself $^{10}$. The direct inhibitory effect of hydroxyapatite on AP, along with the loss of metal ions from the AP active site, are thought to contribute to the decline in AP activity during MV calcification. This mechanism may also be operative in GPBP calcification.

The mechanism by which AP activity is promoted in GPBP mineralization is not yet understood. AP-active sites are activated by metal ions ${ }^{28}$, such as $\mathrm{Zn}^{2+}$ and $\mathrm{Mg}^{2+}$. The $\mathrm{Al}^{3+}, \mathrm{Fe}^{3+}$ and $\mathrm{Ga}^{3+}$ ions probably can compete with $\mathrm{Zn}^{2+}$ and $\mathrm{Mg}^{2+}$ at the enzyme's metallo-binding sites, and thereby inhibit the phosphohydrolase activity. The $\mathrm{Al}^{3+}, \mathrm{Fe}^{3+}$ and $\mathrm{Ga}^{3+}$ ions $\left(10^{-1} \mathrm{M}\right)$ in the GPBP tissues were able to inhibit AP activity, although less so with $\mathrm{Ga}^{3+}$ than the others. However, despite this level of enzyme inhibition by the $\mathrm{Ga}\left(\mathrm{NO}_{3}\right)_{3}$ pre-incubation, this pretreatment was not effective in inhibiting calcification. These results further suggest that, although AP activity may be associated with the onset and progression of GPBP mineralization, it may not be causal or essential for the pathogenesis.

Furthermore, earlier work has shown that either $\mathrm{Al}^{3+}$ or $\mathrm{Fe}^{3+}$ salts act by binding to devitalized GPBP cells, and to membrane loci that are rich in phosphorus, thereby preventing the crystallization of hydroxyapatite at these sites ${ }^{15}$. It may be argued that $\mathrm{Fe}^{3+}$ or $\mathrm{Al}^{3+}$ lowered $\mathrm{AP}$ levels in our studies by a critical increment, thereby reducing GPBP calcification. However, $\mathrm{Al}^{3+}, \mathrm{Fe}^{3+}$ and uther metal ions can inhibit mineralization by other mechanisms. $\mathrm{Al}^{3+}$ ions can absorb on to hydroxyapatite crystals and severely inhibit both hydroxyapatite formation and dissolution in vitro ${ }^{29,30}$. Many metals can interfere with hydroxyapatite crystal growth in vitro by either competing with $\mathrm{Ca}^{2+}$ for sites in the crystal lattice or by adsorbing to the crystal surface ${ }^{31} . \mathrm{Al}^{3+}$ and $\mathrm{Zn}^{2+}$ are found to inhibit MV mineralization ${ }^{32}$. Similarly, in the GPBP subdermal rat implants, the lowest molecular weight metal ions ( $\mathrm{Al}<\mathrm{Fe}<\mathrm{Ga}$, according to atomic weight] showed the strongest inhibitory effects on GPBP calcium accumulation. In fact, the greater the molecular weight of the metal atom of interest, the lower degree of calcification inhibition noted. $\mathrm{Al}^{3+}$, the smallest ion in relation to $\mathrm{Fe}^{3+}$ and $\mathrm{Ga}^{3+}$ was the most effective in calcification inhibition; $\mathrm{Ga}^{3+}$ cation which is the largest metal ion (used in this study) was unable to prevent GPBP calcification. Furthermore, the higher phosphorus content of the $\mathrm{Ga}^{3+} 21 \mathrm{~d}$ explants suggests that high levels of nonapatitic phospho-mineral (perhaps Ga-phosphates) may be predisposed to form after $\mathrm{Ga}^{3+}$ pretreatment. Therefore, these metallic ion pretreatments may be associated with unusual phospho-mineral complexes involving, perhaps, phospholipids or metallo-phosphates other than hydroxyapatite. However, the present experimental design does not permit a conclusive resolution of these issues.

APD pre-incubation inhibited GPBP calcification, but was associated with AP activity higher than controls. APD in clinical use has been associated with adverse effects related to cytotoxicity, as well as inflammatory gastrointestinal and dermatologic side effects ${ }^{33,34}$. The morphological results in the present study demonstrated an exuberant inflammatory response to the APD implants, and thus the higher level of AP may reflect enzyme activity from inflammatory cells or cells damaged due to toxic processes, rather than calcification-related events.
It would have been helpful in this regard to have quantitated the extent of inflammatory cell infiltration. However, this was beyond the scope of the present studies. Furthermore, earlier results from our group have shown that APD pre-incubation of GPBP was associated with unstable covalent binding of APD to GPBP. Thus APD is continuously leaching out of the tissue, and may thereby cause regional toxicity near the GPBP implant. which could lead to increased AP activity related to inflammation, but probably spatially dissociated and unrelated to calcification.

Conversely, NaEHDP pre-incubation, which did not inhibit calcification, resulted in a slightly lower AP activity in the $72 \mathrm{~h}$ explants compared to the controls. However, the net decline in AP activity for the NaEHDP explant groups was comparable to that of calcified controls (Figure 1). Furthermore, previous work from our group has demonstrated that NaEHDP rapidly diffuses out of GPBP tissue following pre-incubation, unlike $\mathrm{Fe}^{3+}, \mathrm{Al}^{3+}$ and $\Lambda \mathrm{PD}$, which remain more closely associated with GPBP tissue ${ }^{35}$. Thus, no persistent anticalcification effects nccurred in the NaF.HDP groun and the decline in AP activity was comparable to controls, as might be expected. In addition, elevated phosphorus levels were noted in the calcified $21 \mathrm{~d}$ $\mathrm{NaEHDP}$ explants, in which a $\mathrm{Ca} / \mathrm{P}$ molar ratio was noted comparable to that of the $\mathrm{Ga}$ explants.

\section{CONCLUSIONS}

The peak levels of AP in rat subdermal GPBP implants were noted at $72 \mathrm{~h}$ in both controls and specimens pretreated with either calcification inhibitors, or related compounds which did not inhibit calcification. Thus, peak GPBP AP activity was present at $72 \mathrm{~h}$, regardless of pretreatment conditions.

All inhibitors of calcification (except APD) were associated with lower $72 \mathrm{~h}$ AP levels than controls, including pretreatments ineffective for calcification inhibition, such as $\mathrm{Ga}^{3+}$ and EHDP. Thus reduced AP at $72 \mathrm{~h}$ is not related to inhibition of calcification.

Therefore, the results of the present experiments support the view that peak AP $(72 \mathrm{~h})$ is not necessarily associated with the ultimate progression GPBP calcification.

\section{REFERENCES}

1 Levy, R.J., Schoen, F.J. and Golomb, G., Bioprosthetic heart valve calcification: clinical features, pathobiology, and prospects for prevention, CRC Crit. Rev. Biocompat. 1986, 2, 147-186

2 Schoen, F.J., Kujovich, J.L., Levy, R.J. and St. John Sutton, M., Bioprosthetic heart valve pathology: clinicopathologic features of valve failure and pathobiology of calcification, Cardiovasc. Clin. 1988, 18, 289-318

3 Schoen, F.J., Cardiac valve protheses: review of clinical status and contemporary biomaterials issues, $J$. Biomed. Mater. Res.: Appl. Biomater. 1987, 21, 91-117

4 Schoen, F.J., Levy, R.J., Nelson, A.C., Bernhard, W.F., Nashef, A. and Hawley. M.. Onset and progression of experimental bioprosthetic heart valve calcification, Lab. Invest. $1985,52,523-532$ 
5 Levy, R.J., Schoen, F.J., Levy, J.T., Nelson, A.C., Howard, S.L. and Oshry, L. . . Biologic determinants of dystrophic calcification and osteocalcin deposition in glutaraldehydepreserved porcine aortic valve leaflets implanted subcutaneously in rats, Am. J. Pathol. 1983, 113, 143-155

6 Schoen, F.J., Kujovich, I.L., Webb, C.L. and Levy, R.J., Chemically determinated mineral content of explanted porcine aortic valve bioprostheses: correlation with radiographic assessment of calcification and clinical data, Circulation 1987, 76, 1061-1066

7 Anderson, H.C., Calcific diseases: a concept, Arch. Pathol. Lab. Med. 1983, 107, 341-348

8 Ali, S.Y. and Anderson, H.C., Isolation and characterization of calcifying MVs from epiphyseal cartilage, Proc. Natl. Acad. Sci. USA 1970, 67, 1513-1520

9 Glazer, J.H. and Conrad, H.E., Formation of matrix vesicles by cultured chick embryo chondrocytes, J. Biol. Chem. 1981, 256, 12607-12611

10 Genge, B.R., Sauer, G.R., Wu, L.N.Y., McLean, F.M. and Wuthier, R.E., Correlation between loss of AP activity and accumulation of calcium during matrix vesicles mediated mineralization, J. Biol. Chem. 1988, 263, 18513-18519

11 Neuman, W.F., Distefano, V. and Mulryan, B.J., The surface chemistry of bone. III Observations on the role of phosphatase, J. Biol. Chem. 1951, 193, 227-235

12 Maranto, A.R. and Schoen, F.J., Alkaline phosphatase activity of glutaraldehyde-treated bovine pericardium used in bioprosthetic cardiac valves, Circ. Res. 1988, 63, 844-848

13 Levy, R.I., Schoen, F.I., Flowers, W.B. and Staelin, S.T., Initiation of mineralization in bioprosthetic heart valves: studies of alkaline phosphatase activity and its inhibition by $\mathrm{AlCl}_{3}$ or $\mathrm{FeCl}_{3}$ preincubations, J. Biomed. Mater. Res. 1991, 25, 905-935

14 Webb, C.L., Flowers, W.E., Boyd, J., Rosenthal, E.L., Schuen, F.J. and Levy, R.J., $\mathrm{Al}^{3+}$ binding studies and metallic cations effects on bioprosthetic heart valve calcification in the rat subdermal model, ASAIO 1990 , 36, 56-59

15 Webb, C.L., Schoen, F.J., Flowers, W.E., Alfrey, A.C., Horton, C. and Levy, R.J., Inhibition of mineralization of glutaraldehyde-pretreated bovine pericardium by $\mathrm{AlCl}_{3}$, Am. J. Pathol, 1991, 138, 971-981

16 Fleish, H., Biophosphonates: a new class of drugs in diseases of bone and calcium metabolism, Recent Results Cancer Res. 1989, 16, 1-28

17 Levy, R.J., Hawley, M.A., Schoen, F.J., Lund, S.A. and Liu, P.Y., Inhibition by diphosphonate compounds of calcification of porcine bioprosthetic heart valve cusps implanted subcutaneously in rats, Lab. Invest. 1985, 71, 349-356

18 Webb, C.L., Schoen, F.J. and Levy, R.J., Covalent binding of aminopropanchydroxydiphosphonate to glutaraldehyde residues in pericardial bioprosthetic tissue: stability and calcification inhibition studies, Exp. Mol. Path. 1989, 50, 291-302

19 Meyer, J.L. and Nancollas, G.H., The influence of multidentate organic phosphonates on the crystal growth of hydroxyapatite, Calcif. Tissue Res. 1973, 13, 293-303

20 Hansen, N.M., Felix, R., Bisaz, S. and Fleisch, H., Aggregation of hydroxyapatite crystals, Biochim. Biophys. Acta 1976, 451, 549-559

21 Felix, R. and Fleisch, H., Increase in alkaline phosphatase activity in calvaria cells cultured with diphosphonates, Biochem. I. 1979, 189, 73-81

22 Felix, R., Herrmann, W. and Fleisch, H., Stimulation of precipitation of calcium phosphate by matrix vesicles, Biochem. J. 1978, 170, 681-691

23 Schoen, F.J., Tsao, I.W. and Levy, R.I., Calcification of bovine pericardium used in cardiac valve bioprostheses. Implications for the mechanisms of bioprosthetic tissue mineralization, Am. J. Pathol. 1986, 123, 134-145

24 Chen, P.S., Toribara, T.Y. and Warner, H., Microdetermination of phosphorus, Anal. Chem. 1956, 28, 1756-1758

25 Lowry, O.H., Rosebrough, N.O. and Farr, A.L., Protein measurement with the Folin phenol reagent, $J$. Biol. Chem. 1951, 193, 265-275

26 Karnovsky, M.J., A formaldehyde-glutaraldehyde fixative of high osmolality for use in electron microscopy, $J$. Cell Biol. 1965, 27, 137 A-138A

27 Gomori, G., Alkaline phosphatase of cell nuclei, $\int$. Lab. Clin. Med. 1951, 37, 526-531

28 Wuthier, R.E. and Register, T.C., Role of alkaline phosphatase, a polyfunctional enzyme, in mineralizing tissues, in The chemistry and biology of mineralized tissues, [Ed W.T. Butler], EBSCO Media, Birmingham, UK, 1985, pp 113-124

29 Blumenthal, N.C. and Pusner, A.S., In vitro model of aluminium-induced osteomalacia: inhibition of hydroxyapatite formation and growth, Calcif. Tissue Int. 1984, 36, 439-441

30 Christoffersen, M.R. and Christoffersen, J., The effect of aluminum on the rate of dissolution of calcium phosphate. A contribution to the understanding of aluminum-induced bone diseases, Calcif. Tissue Int. 1985, 37, 673-676

31 LeGeros, R.Z., Miravite, M.A., Quirolgico, B.G. and Curzon, M.E.J., The effect of some trace elements on the lattice parameters of human and synthetic apatites, Calcif. Tissue Res. 1975, 22, S362-S367

32 Sauer, G.R., Adkisson, H.D., Genge, B.R, and Wuthier, R.E., Regulatory effect of endogenous zinc and inhibitory action of toxic metal ions on calcium accumulation by matrix vesicles in vitro, Bone Miner. 1989, 7, 233244

33 Cal, J.C. and Daley-Yates, P.T., Disposition and nephrotoxicity of 3-amino-1-hydroxypropylidene-1,1-biphosphonate (APD), in rats and mice, Toxicology 1990, 65, 179-197

34 Hintze, K.I. and D'Amato, R.A., Comparative toxicity of two diphosphonates, Toxicologist 1982, 2, 192-195

35 Johnston, T.P., Schoen, F.J. and Levy, R.J., Prevention of calcification of bioprosthetic heart valve leaflets by $\mathrm{Ca}^{2+}$ diphosphonate pretreatment, I. pharm. Sci. 1988, 77, $740-744$ 